\title{
Scientific Europe Turns Into a Fair Mode: Open Access Journals Reducing The Cost of Knowledge
}

\author{
Authors: Gerhard G. Steinmann, Roland Mertelsmann \\ Submitted: \\ Published: \\ Volume: \\ Issue: \\ Affiliation: \\ Languages: \\ Keywords: \\ 10. September 2018 \\ 17. September 2018 \\ 5 \\ 7 \\ IASHA e.V., Freiburg, Germany \\ English \\ Open Access publication, European research funding institutions, \\ Academic publisher oligopoly \\ DOI: $\quad$ 10.17160/josha.5.7.466
}

\section{Abstract:}

According to the Austrian daily „Der Standard” of September 4th, 2018, the Austrian science fonds FWF (Fonds zur Förderung der wissenschaftlichen Forschung), Austria's central institution for the funding of basic research, has communicated that the FWF together with ten other European research funding institutions have committed to require after January 1st, 2020 that all results from research funded by these institutions are published immediately in Open Access journals or platforms. These eleven institutions provide more than half of the European research funding flow. Up to day, only the Bill and Melinda Gates Foundation has pursued a comparable publication policy. As Martin Enserink pointed out on September 9th, 2018 in Science, the institutions do not accept any more delays of up to a year before an article is made openly accessible after submission to a journal or any additional charges for the Open Access

\section{JOSHA \\ Journal of Science, Humanities and Arts}




\section{Scientific Europe Turns Into a Fair Mode: Open Access Journals Reducing The Cost of Knowledge}

\section{by Gerhard G. Steinmann and Roland Mertelsmann}

According to the Austrian daily „Der Standard” of September 4th, 2018, the Austrian science fonds FWF (Fonds zur Förderung der wissenschaftlichen Forschung), Austria's central institution for the funding of basic research, has communicated that the FWF together with ten other European research funding institutions have committed to require after January 1st, 2020 that all results from research funded by these institutions are published immediately in Open Access journals or platforms. These eleven institutions provide more than half of the European research funding flow. Up to day, only the Bill and Melinda Gates Foundation has pursued a comparable publication policy. As Martin Enserink pointed out on September 9th, 2018 in Science, the institutions do not accept any more delays of up to a year before an article is made openly accessible after submission to a journal or any additional charges for the Open Access publication. - This is good news!

Since decades, publications in research and science have been ruled by privately owned scientific journals, who have gradually increased the cost pressure to scientific libraries and researchers to an agonizing level. In parallel, scientific publishing houses have grown to multibillion concerns. Currently, about five global players lead the scientific publication party, including Reed-Elsevier, Springer Nature, Wiley-Blackwell, Taylor \& Francis and Sage (cf. sciencev2.orf.at/stories/1759657/index.html ).

Vincent Larivière and colleagues have analyzed 45 million scientific papers, which have been published from 1973 to 2013. Their results appeared under the alarming title "The Oligopoly of Academic Publishers in the Digital Era" on June 10th, 2015 in PLOS ONE and evidenced that the five major publishing houses took control of more than $50 \%$ of the publication market and generated an operating margin of about $40 \%$ based on products they simply did not pay for. 
These companies continue to take a free ride on the back of research, which is funded or sponsored by others, in most cases by public funds, and which is subsequently evaluated by researchers on the basis of voluntary and unsalaried peer review.

In the face of these unsatisfying conditions, the decision of the eleven European research institution is a blessing for all campaigners and pioneers for a free access to results of research that is funded by the public, including British mathematician Timothy Gowers, who initiated the successful boycott initiative "Cost of Knowledge" against business practices of Dutch publisher Elsevier. As of today, 17,217 researchers have taken a stand, cf. http://thecostofknowledge.com/. Opportunely, also the EU commissioner for Research, Science and Innovation Carlos Moedas advised the European Parliament and the European Council to adopt regulations similar to the new requirements of the eleven European research funding institutions (Science September 7, 2018, vol 361 issue 6406 p 957).

Under the term "Plan S", Europe has pushed the Open Access policy in the recent years, but without cost awareness and visible progress. Announced in 2016, target was to make all new research articles publicly available from the year 2020 onwards. Under "Plan S", authors retain the copyright and are entitled to reuse their article for additional publications. The funders carry any submission or publication fee as determined by the publisher. Only now, the awareness has grown that payments to publishers have doubled, a first time for the publication fee and a second time for the subscription of the journal.

Open Access publication is definitely one of the most effective measures against the oligarchy of scientific publishers and the disadvantages in efficiency and fairness associated with economic oligopoly. The article „Gleich doppelt abkassiert - Wissenschaftler wehren sich gegen die Marktmacht der Verlage“ of journalist Andreas Sentker in DIE ZEIT Nr. 53/2016, describes how persistent and tenacious Elsevier fights for its revenues in the light of changing paradigms due to Open Access publications. To begin with, Elsevier has recently closed access to its journals to non-cooperating universities and research facilities in Germany and Sweden. In the subsequent negotiations and in current practice, submission fees of several thousands of Euro per submission are on the brink for evaluation, editorial office and distribution. And that's not all - considerable subscription fees for academic libraries remain in addition. The urgings were defended by questionable arguments including cost of peer review procedures and importance of impact factors. According to Martin Enserink, reactions of traditional publishers to the new move of the eleven European funding institutions include allegations like "undermining the whole research publishing system", "disrupting scholarly communications" and "impinge academic freedom". 
In 2016, three leading European Academies of Sciences, the German Leopoldina, the French Académie des Sciences and the British Society, have agreed on indisputable, but very universal and general guidelines of a Good Scientific Publication Practice. Scientific information should be provided efficiently and at high quality, conflict of interest should be avoided, papers should be checked fairly and selection und compilation should remain in the responsibility of accepted scientists.

We, the editors of JOSHA, know that Open Access publications cannot be provided for free. The procedures are associated with a certain, but limited amount of cost. This cost, in the case of JOSHA, is covered by two philanthropic institutions, the Academy of Science, Humanities, and Arts (IASHA e.V.) and the Biothera-Roland Mertelsmann Foundation. We, however, are distressed by the demands of the oligarchy. We also do not believe that impact factors and current peer review procedures are essential for an efficient, high-quality publication policy without conflict of interest. In the past, many signals have indicated that the contrary may be true. In contrast, we are convinced that an Open Access journal with an editorial board of few accepted full-time scientists may effectively communicate honest work as speedily and as broadly as possible.

We congratulate the Austrian FWF and the ten other European research funding institutions for their forward-looking funding policy. 